\section{Huge Ancient Hematoma in the Calf}

Kyeong Beom Choi, Yu Jin Jang, Myong Chul Park, Dong Ha Park, Il Jae Lee

Department of Plastic and Reconstructive Surgery, Ajou University Hospital, Ajou University School of Medicine, Suwon, Korea

\section{Correspondence: II Jae Lee}

Department of Plastic and Reconstructive Surgery, Ajou University Hospital, Ajou University School of Medicine, 164 Worldcup-ro, Yeongtong-gu, Suwon 16499, Korea

Tel: +82-31-219-5614, Fax: +82-31-219-5610, E-mail: i00325@live.co.kr

This article was first presented at the 71st Congress of Korean Plastic and Reconstructive Surgeons, November 2-4, 2013 in Seoul, Korea.

No potential conflict of interest relevant to this article was reported.

Received: 12 Jan 2015 • Revised: 26 Feb 2015 • Accepted: 12 Mar 2015 pISSN: 2234-6163 • elSSN: 2234-6171

http://dx.doi.org/10.5999/aps.2016.43.1.105

Arch Plast Surg 2016;43:105-107

Copyright (C) 2016 The Korean Society of Plastic and Reconstructive Surgeon This is an Open Access article distributed under the terms of the Creative Commons Attribution Non-Commercial License (http://creativecommons.org/licenses/by-nc/3.0) which permits unrestricted non-commercial use, distribution, and reproduction in any medium, provided the original work is properly cited.

Ancient hematoma is one of several lesions that require differentiation from soft tissue neoplasm. This hematoma, named as such by Mentzel et al. [1], is a benign soft tissue tumor surrounded by a fibrous pseudocapsule with inflammatory cells present inside

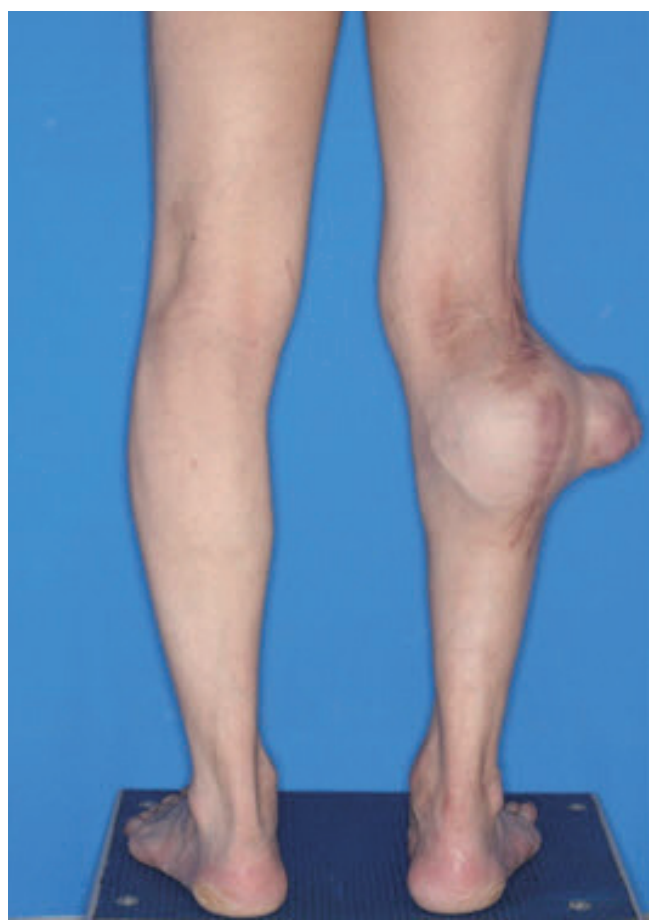

Fig. 1.

Preoperative photograph. the capsule that gradually expands in size. Chronic expanding hematoma, designated by Reid et al. [2], is a hematoma that increases slowly in size over more than a month after onset. Ancient hematoma is also called chronic expanding hematoma in the field of clinical medicine. It can mimic soft tissue sarcoma because of its increasing size after the initial hemorrhage

A 44-year-old male complained of a protruding giant mass $(10 \mathrm{~cm} \times 15 \mathrm{~cm})$ in his right calf and numbness of his right leg due to compression by the mass (Fig. 1). The patient had no history of medical disease but a history of trauma involving a pedestrian traffic accident 20 years previously. He had a $16-\mathrm{cm}$ vertical postoperative scar in his right calf after a right knee operation conducted at the time of accident. Unfortunately, the nature of the knee operation could not be established since the records of the surgery were no longer available. At the time, the mass had been palpable 2 weeks after the knee surgery, but no treatment had been done.

The mass was evaluated from radiologic findings. Contrast computed tomography (CT) revealed a huge lobulated cystic mass at the intermuscular septal and subcutaneous fat layer level. Internal scattered calcification and septation were found; they were suggestive of post-trauma cyst, extra-skeletal chondrosarcoma, and synovial sarcoma. A magnetic resonance imaging (MRI) scan with contrast enhancement suggested post-traumatic giant epidermal inclusion cyst or malignant fibrous histiocytoma (Fig. 2). To rule out malignancy and evaluate pathology, ultrasonography-guided needleaspiration biopsy was done. Soft tissue fragments and reddish aspirates were obtained, which were suggestive of a post-traumatic epidermal cyst or sarcoma.

Surgical exploration under general anesthesia revealed a pseudocapsulated mass measuring 11

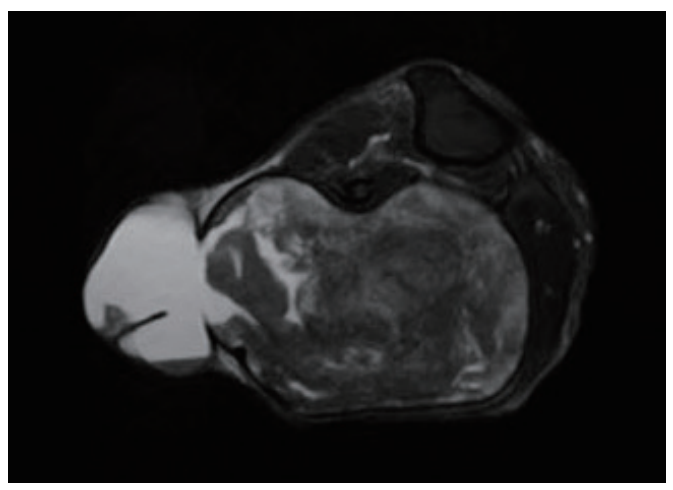

Fig. 2.

Magnetic resonance imaging showing mass located in the intermuscular septum, between the gastrocnemius muscle and soleus muscle. It was suggested posttraumatic giant epidermal inclusion cyst or malignant fibrous histiocytoma. 


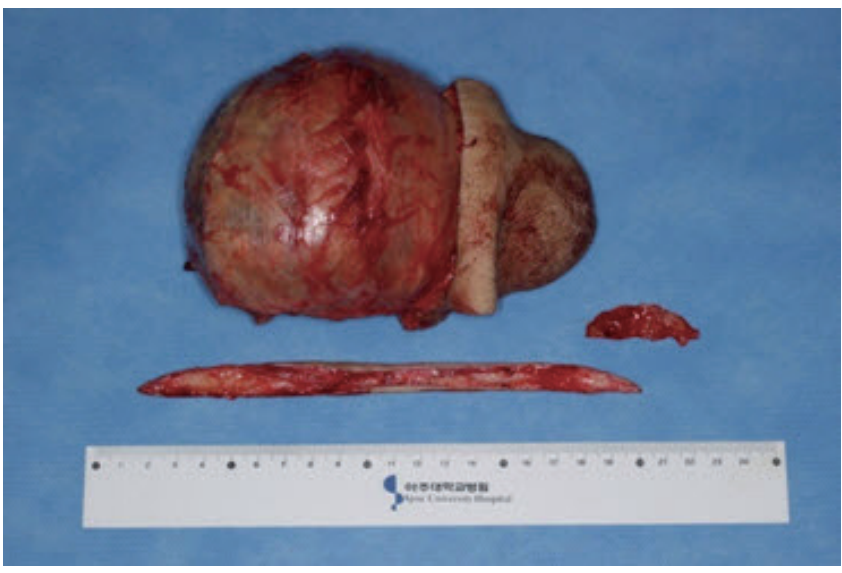

Fig. 3.

The $11 \mathrm{~cm} \times 11 \mathrm{~cm} \times 10 \mathrm{~cm}$-sized mass was completely excised. The mass was encapsulated by fibrous cyst.

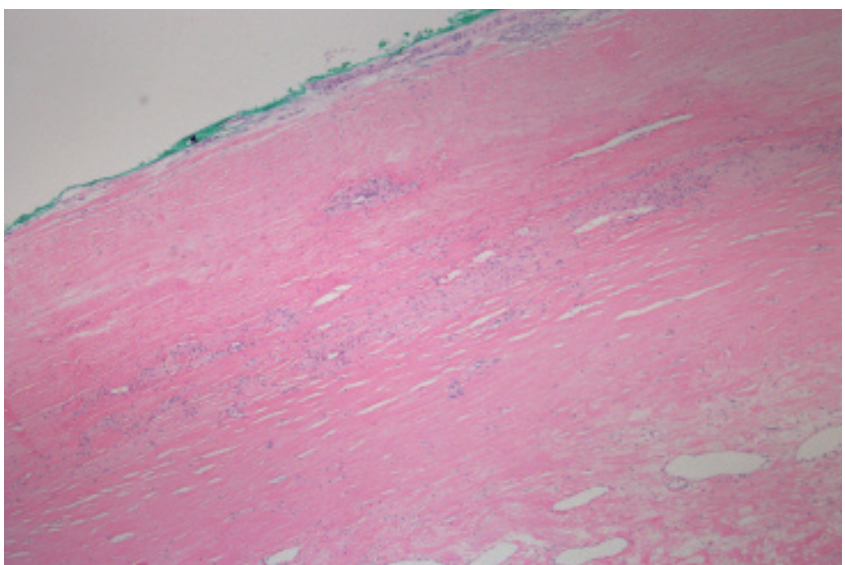

Fig. 4.

Histologic findings include fibrous cyst and infiltration of immune cells. Fibrous tissue and blood vessels were also found in mass $\left(H \& E_{1} \times 100\right)$. $\mathrm{cm} \times 11 \mathrm{~cm} \times 10 \mathrm{~cm}$ in the intermuscular septum between the gastrocnemius and the soleus muscle (Fig. 3). Incision was done using the previous operation scar line. With careful dissection, excision was complete. Despite many efforts to excise the mass between the medial and the lateral head of the gastrocnemius muscle, it was impossible to excise the mass without damaging the adjacent muscle. We resected the lateral head of the gastrocnemius muscle and repaired it meticulously after the complete excision. After excising the mass, we performed frozen biopsy and no malignancy cell was found. Histopathologically, the mass was composed of the neovascularized infiltrate of immune cells, particularly histiocytes and calcific myonecrosis, which are typical characteristics of ancient hematoma (Fig. 4).

The wound was completely healed after 1 month and the patient had no trouble with walking. We evaluated the patient's bleeding tendency at 2 months postoperatively, including prothrombin time, partial thromboplastin time, bleeding time, antinuclear antibodies, anti-double stranded deoxyribonucleic acid, protein C, anti-thrombin III, factor V, factor XIII, and fibrin degradation product. All parameters were in their normal range. Six months postoperatively (Fig. 5), motor exams including knee and ankle joint motion and sensory function test including two-point discrimination were done. All results were within the normal range, and there was no evidence of recurrence. Although we resected the lateral head of the gastrocnemius muscle and calf, healing occurred without motor or sensory dysfunctions. We recommended that the patient receive a fat graft on the depressed calf, but the patient refused.

Hematoma is easy to diagnose on the basis of patient history, such as medical and surgical findings, local findings, and clinical course. However, ancient hematoma is very rare and the diagnosis is based on the exclusion of other pathologies. The protracted time interval between trauma or surgery and mass development can hinder the diagnosis.

The pathophysiology of ancient hematoma remains unclear. Labadie and Glover [3] reported that blood and erythrocyte degradation products, hemoglobin, leukocytes, platelets, and fibrin irritate the surrounding tissue. These factors are believed to induce a mild inflammatory response, which increases vascular wall permeability and bleeding from dilated capillaries in the granulation tissue beneath the capsular wall, resulting in the subsequent growth of the hematoma [3]. However, no bleeding risk was identified in the present case. In our case, we suspect that the hematoma that was not removed sufficiently during previous surgery could have been the origin of the subsequent hematoma.

Radiologic exams, particularly MRI, can be used to help the diagnosis of the soft tissue tumor. The signal within the lesion on MRI can vary with time, indicating time-related changes in hemoglobin levels [4]. A few soft tissue tumors, such as lipomas, liposarcomas, and hemangiomas, also yield enhanced high signal intensity on T1-weighted images [4]. However, the differentiation of hematomas from malignant soft tissue tumors based on clinical and radiological findings can be difficult because of the time-related changes in MRI signals [4]. 


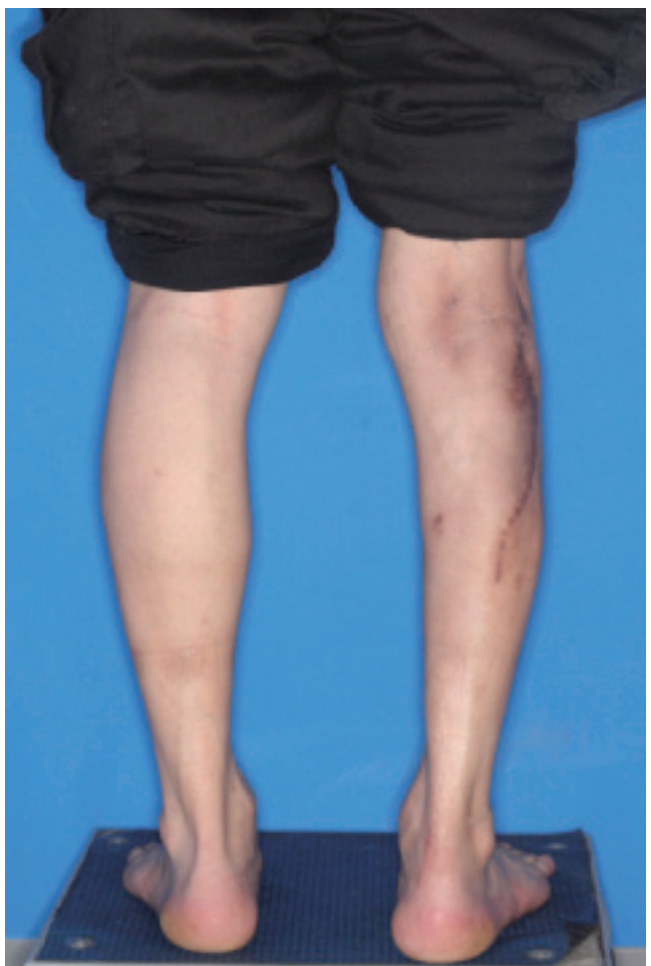

Fig. 5.

Postoperative photograph. Six months after operation.

A search of PubMed articles published from 1970 to 2012 identified 208 cases of ancient hematoma. Of these, 79 cases were in the brain, 59 cases were in the thorax, 36 cases were in the lower extremity, 10 cases were in the abdomen, and 24 cases were in the upper extremity. Only three cases originated from the calf. Of the three cases, one involved a 75-year-old male who received coumadin therapy for deep vein thrombosis. The second case involved a 76-year-old male who had experienced trauma on the soleus muscle 34 years previously. During surgery to remove the hematoma, the soleus muscle was completely resected. The report of the third case did not describe the patient's history. Unlike the other reported cases we reviewed in the literature, the present case had no bleeding risk, including old age. Although we resected the lateral head of the gastrocnemius muscle and calf, healing occurred without motor or sensory dysfunctions.

Hematoma commonly arises right after trauma or operation. The protracted time after trauma or the inability to identify the nature of prior surgery makes it difficult to diagnose an ancient hematoma. A calf is not a common part of the body from which a hematoma originates. The present case had no bleeding risk including old age, which makes the diagnosis more difficult. As far as we know, this is the first case report of ancient hematoma originating from the calf in a patient, who was not in old age and had no other bleeding risk.

\section{References}

\section{Mentzel T, Goodlad JR, Smith MA, et al. Ancient} hematoma: a unifying concept for a post-traumatic lesion mimicking an aggressive soft tissue neoplasm. Mod Pathol 1997;10:334-40.

2. Reid JD, Kommareddi S, Lankerani M, et al. Chronic expanding hematomas. A clinicopathologic entity. JAMA 1980;244:2441-2.

3. Labadie EL, Glover D. Physiopathogenesis of subdural hematomas. Part 1: Histological and biochemical comparisons of subcutaneous hematoma in rats with subdural hematoma in man. J Neurosurg 1976;45:38292.

4. Negoro K, Uchida K, Yayama T, et al. Chronic expanding hematoma of the thigh. Joint Bone Spine 2012;79:192-4.

\section{Salivary Duct Carcinoma of the Deep Lobe of the Parotid Gland: A Rare Clinical Finding}

Hi-Jin You, Tae-Kyoung Yun, Seong-Ho Jeong, Eun-Sang Dhong, Seung-Kyu Han

Department of Plastic Surgery, Korea University College of Medicine, Seoul, Korea

Correspondence: Hi-Jin You

Department of Plastic Surgery, Korea University Ansan Hospital, 123 Jeokgeum-ro, Danwon-gu, Ansan 15355, Korea

Tel: +82-31-412-4288, Fax: +82-31-475-5074, E-mail: hijinyou@gmail.com

This article was presented at the Fourth Research and Reconstructive Forum on April 3-4, 2014, in Busan, Korea.

No potential conflict of interest relevant to this article was reported.

Received: 21 Jan 2015 • Revised: 10 Apr 2015• Accepted: 7 May 2015 pISSN: 2234-6163 • elSSN: 2234-6171 http://dx.doi.org/10.5999/aps.2016.43.1.107 Arch Plast Surg 2016;43:107-110

Copyright (C) 2016 The Korean Society of Plastic and Reconstructive Surgeons

This is an Open Access article distributed under the terms of the Creative Commons Attribution Non-Commercial License (http://creativecommons.org/licenses/by-nc/3.0/) which permits unrestricted non-commercial use, distribution, and reproduction in any medium, provided the original work is properly cited.

Salivary duct carcinoma is a rare malignant tumor that resembles high-grade breast ductal carcinoma. It was first described by Kleinsasser et al. [1] in 1968, 